\title{
Ethnopharmacological evaluation of schistosomicidal and cercaricidal activities of some selected medicinal plants from Ghana
}

Desmond Omane Acheampong ${ }^{1 *}$, Ninette Owusu-Adzorah ${ }^{1}$, Francis Ackah Armah', Enoch Aninagyei ${ }^{2}$, Ernest Amponsah Asiamah', Ama Kyeraa Thomford ${ }^{1}$ and William Kofi Anyan ${ }^{3^{*}}$

\begin{abstract}
Background: The adulticidal and cercaricidal activities of five Ghanaian medicinal plants, namely, Phyllanthus amarus, Vernonia amygdalina, Azadirachta indica, Morinda lucida and Nauclea latifolia against S. mansoni were evaluated in this study. Six weeks old ICR mice $(n=25)$ were percutaneously infected with S. mansoni cercariae. Nine weeks later, infected mice $(n=5)$ were anaesthetised and perfused for adult $S$. mansoni. Cercariae were treated with different concentrations $(1000,500,250,125,62.5,31.25 \mu \mathrm{g} / \mathrm{mL})$ of methanolic extracts of the experimenting plants in triplicates. Adult S. mansoni incopula were also treated with same concentrations of each extract or $20 \mu \mathrm{g} / \mathrm{mL}$ praziquantel. The cercariae and adult worms were observed at time intervals for $180 \mathrm{~min}$ and $120 \mathrm{~h}$ to assess mortality and viability respectively. Additionally, 9-week cercariae-infected mice (4 groups of 5 mice) were treated with either $500 \mathrm{mg} / \mathrm{kg}$ po A. indica or V. amygdalina, $400 \mathrm{mg} / \mathrm{kg}$ po praziquantel or distilled water for 14 days. The mice were euthanized after adult worms were recovered from them. The liver was processed and histologically examined for granuloma formations.

Results: All the plants exhibited varying cercaricidal and adulticidal activities against S. mansoni in a time and concentration-dependent manner. A. indica $(3 \mathrm{~h} \mathrm{IC} 50=27.62 \mu \mathrm{g} / \mathrm{mL})$ and $V$. amygdalina $(3 \mathrm{~h} \mathrm{IC} 50=35.84 \mu \mathrm{g} / \mathrm{mL})$ exerted the highest cercaricidal activity. Worm recovery after treatment with $V$. amygdalina, $A$. indica and praziquantel in vivo was $48.8 \%, 85.1 \%$ and $59.9 \%$ respectively $(p<0.05)$. A. indica and $V$. amydalina-treated mice recorded lesser mean liver and spleen weights compared to untreated groups $(p<0.05)$.

Conclusion: A. indica demonstrated the highest cercaricidal and alduticidal activities in vitro, whereas $V$. amygdalina exhibited the most potent aldulticidal activity in vivo. This study could provide baseline information which can be used to develop plant-based alternative commercial drugs against S. mansoni.
\end{abstract}

Keywords: Cercariae, Schistosoma mansoni, Azadirachta indica, Vernonia amygdalina

\footnotetext{
* Correspondence: dacheampong@ucc.edu.gh; wanyan@noguchi.ug.edu.gh

${ }^{1}$ Department of Biomedical Sciences, School of Allied Health Sciences,

College of Health and Allied Science, University of Cape Coast, Cape Coast,

Ghana

${ }^{3}$ Noguchi Memorial Institute for Medical Research, College of Health

Sciences, University of Ghana, Legon, Ghana

Full list of author information is available at the end of the article
}

(C) The Author(s). 2020 Open Access This article is licensed under a Creative Commons Attribution 4.0 International License, which permits use, sharing, adaptation, distribution and reproduction in any medium or format, as long as you give appropriate credit to the original author(s) and the source, provide a link to the Creative Commons licence, and indicate if changes were made. The images or other third party material in this article are included in the article's Creative Commons licence, unless indicated otherwise in a credit line to the material. If material is not included in the article's Creative Commons licence and your intended use is not permitted by statutory regulation or exceeds the permitted use, you will need to obtain permission directly from the copyright holder. To view a copy of this licence, visit http://creativecommons.org/licenses/by/4.0/. 


\section{Background}

Schistosomiasis is a parasitic disease caused by the blood fluke Schistosoma and remains one of the important neglected tropical diseases globally. The average treatment cost per person per day is estimated to be $\$ 0.2$ $1.0[1,2]$. The disease affects over 250 million people worldwide and causes, at least, 200,000 deaths annually [3]. Clinical manifestation includes, but not limited to, abdominal pain, hematuria, hematochezia and diarrhoea. In extreme cases, chronic schistosomiasis results in stunted growth and neurological disorders leading to learning difficulties, multi-organ damage, immunocompromised system and, ultimately, death [4]. In Schistosoma-endemic countries, poverty is further deepened because the condition drastically reduces productivity. Currently, praziquantel (PZQ) is the drug of choice for treating human schistosomiasis [5]. Nevertheless, praziquantel has failed in many cases of juvenile worm (schistosomulae) infections because of drug insensitivity [6]. It is, therefore, imperative to find alternative therapies which are relatively affordable and readily available in the community.

A fundamental problem associated with the treatment of schistosomiasis and other infectious diseases is that, the pathogens mutate following selective pressure from the therapeutic agents. Additionally, in endemic countries, the disease is predominant in villages; treatment programmes, which are free, are mostly run in schools. Unfortunately, most of the children are seldomly in school, and some infected individuals are beyond school-going age. The infected individuals who are not covered by the treatment programme have to self-get the treatment regimen which, in most cases, is unaffordable to them $[7,8]$. The aforementioned reasons necessitates the search for alternative therapies which are affordable and easily accessible to these category of people.

In Ghana, Schistosoma haematobium and Schistosoma mansoni are the main flukes that cause schistosomiasis [9]. The respective intermediate hosts, Bulinus trancatus/globossus and Biomphalaria pfeifferi, have been identified in several water bodies in Ghana [10]. Two stages in the life cycle of the parasitic helminth, miracidium and cercariae, are involved in the invasion of their hosts. Miracidium and cercariae respectively infect the intermediate host, snail, and definitive host, man [11]. Potential therapy targeted at any of the stages of the parasite's life cycle could lead to treatment success.

Plants have played crucial roles in drug discovery and development by providing lead compounds for drug development [12]. Pathogens hardly develop resistance to their metabolites in most cases [13]. In view of these, plants and other natural products are mostly screened for metabolites with prophylactic and/or therapeutic potential against various conditions, including parasitic infections. For diseases of tropical origin, plant-based drugs come in handy partly; most tribes, due to have cultural connotations (folklore), perceive herbal medicine to be less toxic [14]. A large number of plant families with potential schistosomicidal activity have been identified through plant screening, which represents a continuous effort to find new bioactive molecules [15]. In Ghana, several plants (Combretum mucronatum, Paullinia pinnata and Phyllanthus urinaria) are used for treatment of helminth infections [16]; however, their cercaricidal and schistosomicidal properties have not been empirically assessed. This study, therefore, evaluated the cercaricidal and adulticidal activities of Azadirachta indica, Morinda lucida, Nauclea latifolia, Phyllanthus amarus and Vernonia amygdalina on S. mansoni.

\section{Results}

\section{Cercaricidal activity of extracts}

Apart from Balanites aegyptiaca (positive control), the line graph of most of the extract concentrations remained steady at $0 \%$ mortality for $60 \mathrm{~min}$ or $120 \mathrm{~min}$ before they recorded a steady rise in percent mortality. The time-course graph for $1000 \mu \mathrm{g} / \mathrm{mL}$ Nauclea latifolia and Azadirachta indica rather followed an unusual pattern. The $1000 \mu \mathrm{g} / \mathrm{mL}$ extracts of $N$. latifolia and $A$. indica recorded a decline in mortality from 15 to $30 \mathrm{~min}$ before a steady rise. The test extracts achieved 100\% mortality later than $30 \mathrm{~min}$, in contrast to, B. aegyptiaca $(125-1000 \mu \mathrm{g} / \mathrm{mL})$, which produced $100 \%$ mortality from 15 to $30 \mathrm{~min}$ (Fig. 1a). Among the test extracts, only $250 \mu \mathrm{g} / \mathrm{mL}$ A. indica exhibited $100 \%$ mortality at $60 \mathrm{~min}$; all other extract regimen achieved 100\% mortality at $120 \mathrm{~min}$. In Fig. 1, B. aegyptiaca, produced $100 \%$ mortality at 15 and $30 \mathrm{~min}$ at $125 \mu \mathrm{g} / \mathrm{mL}$ while $V$. amygdalina produced $98 \%$ mortality at $30 \mathrm{~min}$ with $250 \mu \mathrm{g} /$ mL. Also, A. indica produced $100 \%$ mortality at concentrations from $250 \mu \mathrm{g} / \mathrm{mL}$ from $30 \mathrm{~min}$ and above while $N$. latifolia also produced $100 \%$ mortality at concentrations $250 \mu \mathrm{g} / \mathrm{mL}$ whereas $M$. lucida and $P$. amarus treatment had the highest onset of action with activity at 120th minute.

Additionally, B. aegyptiaca recorded the least $\mathrm{IC}_{50}$ values at all-time points. $A$. indica was next to record an $\mathrm{IC}_{50}$ value at $30 \mathrm{~min}$ and second smallest $\mathrm{IC}_{50}$ value for the remaining time points. Vernonia amygdalina was next with its first $\mathrm{IC}_{50}$ recorded at $60 \mathrm{~min}$ and third smallest $\mathrm{IC}_{50}$ value after $A$. indica and $B$. aegyptica for the remaining time points. Morinda lucida and N. latifolia were next to record their first $\mathrm{IC}_{50}$ values but at 120 min. However, $N$. latifolia recorded a smaller $\mathrm{IC}_{50}$ value than $M$. lucida and also for the remaining time points. $P$. amarus was the last to record an $\mathrm{IC}_{50}$ value at 180 min (Table 1). At the end of $180 \mathrm{~min}$, the $\mathrm{IC}_{50}$ values 


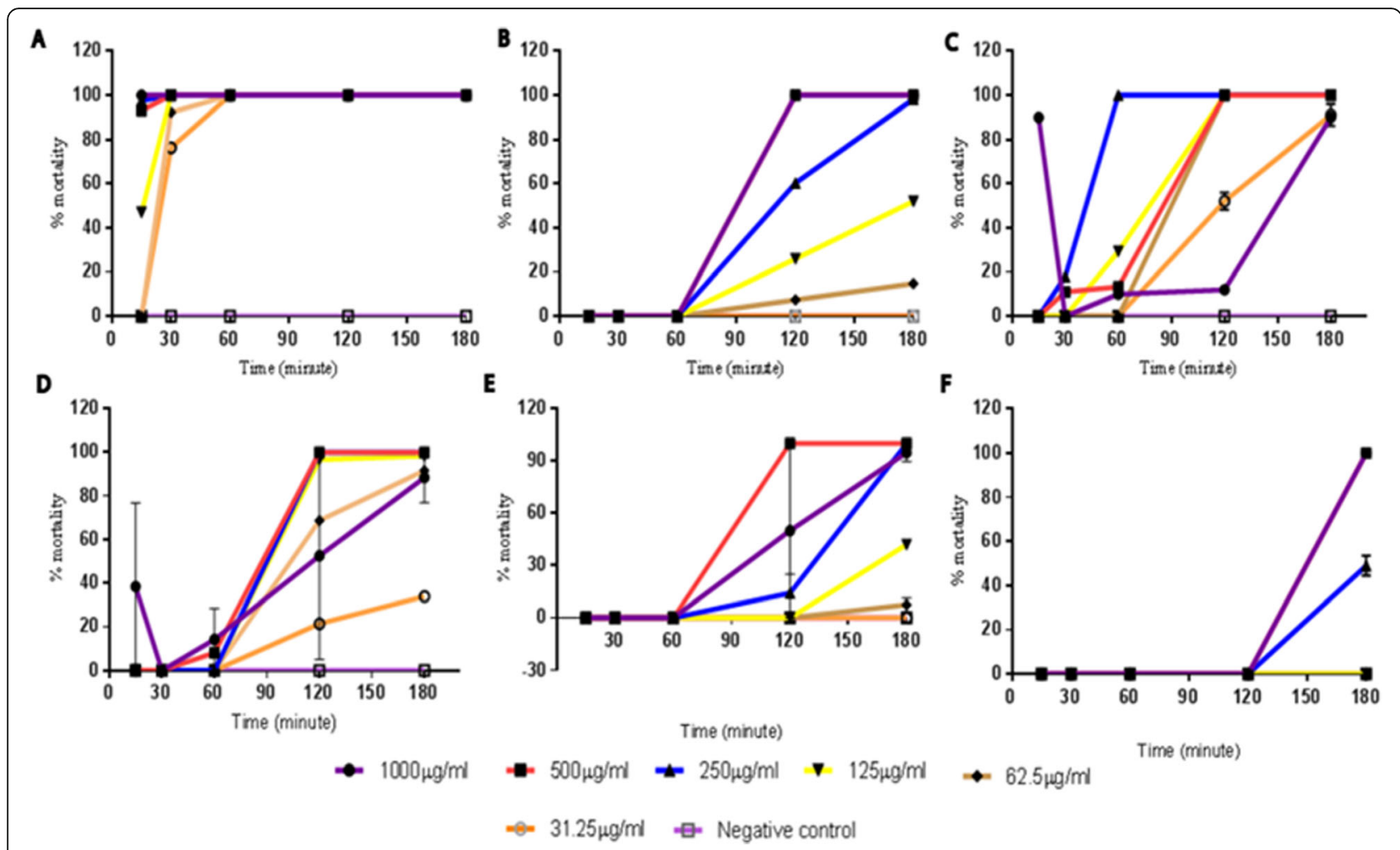

Fig. 1 Time course mortality rate of the cercariae after treatment with the plant extracts. The percent mortality rate of cercariae after 180 min. a $B$. aegyptica. b V. amygdalina. c $A$. indica. d N. latifolia. e M. lucida. $\mathbf{f} P$. amarus

from least to highest were $5.959 \mu \mathrm{g} / \mathrm{mL}$ (Balanites aegyptiaca), $27.62 \mu \mathrm{g} / \mathrm{mL}$ (Azadirachta indica), $35.84 \mu \mathrm{g} / \mathrm{mL}$ (Vernonia amygdalina), $117.7 \mu \mathrm{g} / \mathrm{mL}$ (Nauclea latifolia), $131.9 \mu \mathrm{g} / \mathrm{mL}$ (Morinda lucida) and $250.4 \mu \mathrm{g} / \mathrm{mL}$ (Phyllanthus amarus) (Table 1).

\section{Adulticidal effect of plant extracts}

\section{Viability of adult schistosome worms in vitro}

At the end of $120 \mathrm{~h}$, most of the test extracts and praziquantel (positive control) were lethal to the adult incopula. The extract concentrations which reduced the viability scale from 3 to 0 include $62.5-1000 \mu \mathrm{g} / \mathrm{mL}$ A. indica, 125$1000 \mu \mathrm{g} / \mathrm{mL}$ M. lucida and P. amarus, 250-1000 $\mu \mathrm{g} / \mathrm{mL} V$.

Table $1 \mathrm{IC}_{50}$ values of various extracts in $\mu \mathrm{g} / \mathrm{mL}$ of the different time intervals

\begin{tabular}{llllll}
\hline & \multicolumn{5}{l}{$\mathrm{IC}_{50}$ Values of extracts $(\mu \mathrm{g} / \mathrm{mL})$} \\
\cline { 2 - 6 } & $15 \mathrm{~min}$ & $30 \mathrm{~min}$ & $60 \mathrm{~min}$ & $120 \mathrm{~min}$ & $180 \mathrm{~min}$ \\
\hline Balanites aegyptiaca & 127.5 & 18 & 5.959 & 5.959 & 5.959 \\
Azadirachta indica & $\sim$ & $>1000$ & 127.8 & $\sim 31.22$ & 27.62 \\
Morinda lucida & $\sim$ & $\sim$ & $\sim$ & 262.3 & 131.9 \\
Nauclea latifolia & $\sim$ & $\sim$ & $\sim$ & 195.9 & 117.7 \\
Phyllanthus amarus & $\sim$ & $\sim$ & $\sim$ & $\sim$ & 250.4 \\
Vernonia amygdalina & $\sim$ & $\sim$ & $>1000$ & 48.1 & 35.84 \\
\hline
\end{tabular}

amygdalina and $500-1000 \mu \mathrm{g} / \mathrm{mL} N$. latifolia. The negative control did not reduce the viability of the adult incopula throughout the experimental period (Fig. 2). It was noted that $N$. latifolia produced no worm viability after $48 \mathrm{~h}$ for any of the concentrations while $V$. amygdalina produced activity after $24 \mathrm{~h}, 48 \mathrm{~h}$ and $72 \mathrm{~h}$ for $1000 \mu \mathrm{g} / \mathrm{mL}, 500 \mu \mathrm{g} /$ $\mathrm{mL}$ and $250 \mu \mathrm{g} / \mathrm{mL}$ respectively. Also $M$. lucida and $A$. indica produced no activity after $24 \mathrm{~h}$ for $24 \mathrm{~h}$. Also $P$. amarus produced no mortality after $24 \mathrm{~h}$ for all the concentrations. There was however no statistical difference between $A$. indica and PZQ.

\section{Percentage worm recovery and worm burden}

Further, $A$. indica and $V$. amygdalina plant extracts were selected for the in vivo studies based on their high in vitro schistosomicidal and cercaricidal activities. Oneway analysis of variance (ANOVA) test showed that at least one of the mean numbers of adult worms recovered for a treatment group differed from another $(F=$ 7.327, $p=0.0026)$. Post hoc analysis showed that the mean number of worms recovered from $V$. amygdalina $(12.00 \pm 1.549)$, A. indica $(19.80 \pm 8.194)$ and praziquantel $(13.60 \pm 3.600)$-treated $S$. mansoni infected mice was significantly lesser than that of the untreated group $(40.20 \pm 3.072)$ (Table 2, Fig. 3). 


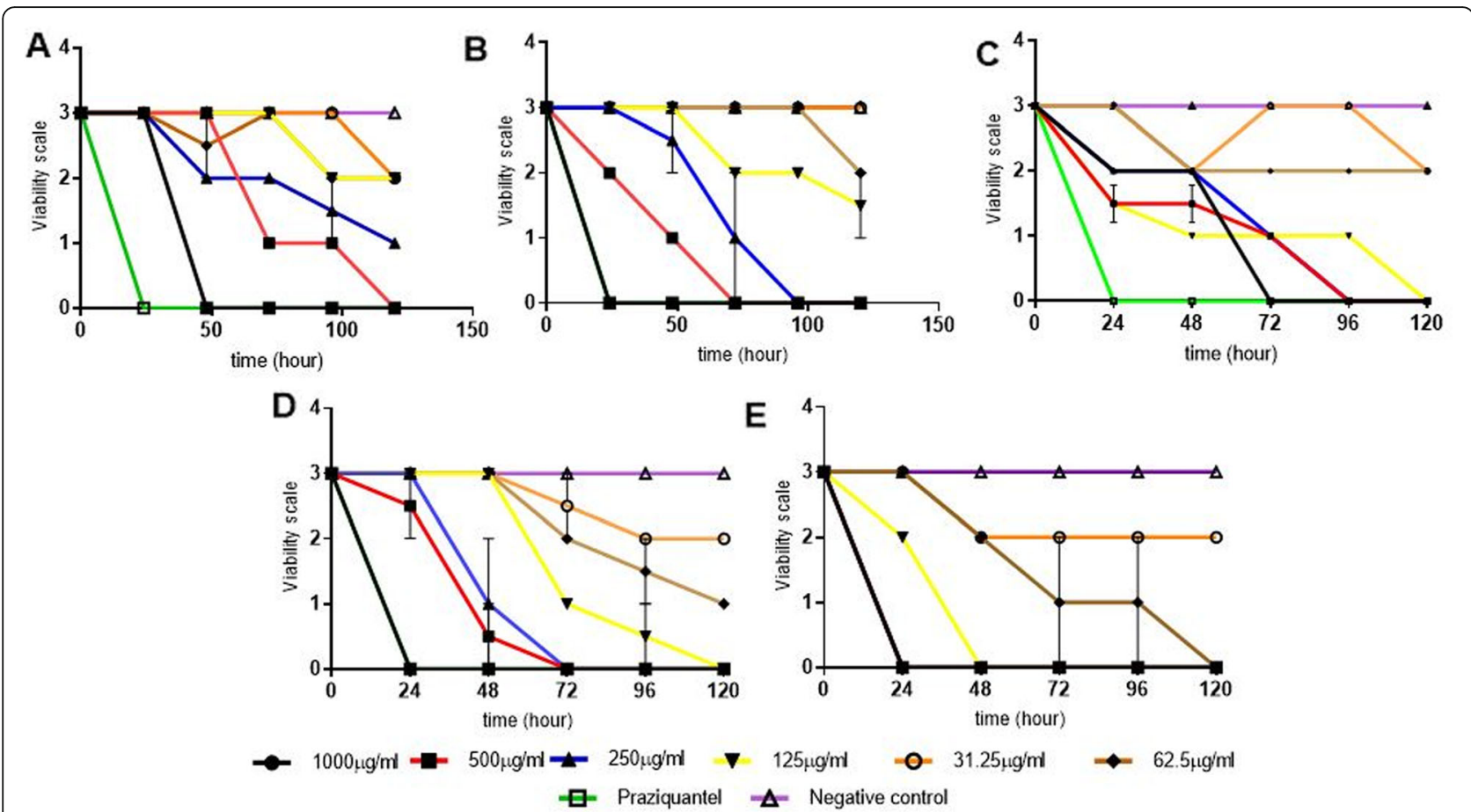

Fig. 2 Anti-schistosomal activity of extracts. The percent mortality rate of the adult worm after N. latifolia (a), V. amygdalina (b), M. lucida (c), P. amarus (d) and A. indica (e) treatment. There was however no statistical difference between A. indica and PZQ

The mean percentage worm recovery values for the groups of mice treated with $V$. amygdalina, $A$. indica and praziquantel were $48.9 \%, 85.1 \%$ and $59.9 \%$ respectively; they were significantly lesser than that of the untreated group (Fig. 4). However, there was no significant difference among the worm recovery values $(p$ value $=$ 0.669 ) of the treatment groups. The mean worm burden in the mice treated with $V$. amygdalina and praziquantel was 2 , whereas, that of $A$. indica-treated and untreated mice scored a mean worm burden of 3 . However, there was no significant difference in worm burden among the treatment options $(p=0.727)$. The average percentage worm recovery for the groups of mice treated with $V$. amygdalina, A. indica and praziquantel (positive control) was $48.9 \%, 85.1 \%$ and $59.9 \%$ respectively, relative to $100 \%$ recorded for the untreated mice (Fig. 4). However, there was no significant difference between the worm recovery following the treatment with $V$. amygdalina, $A$. indica and PZQ ( $p$ value $=0.669)$.

Table 2 Worms recovered from S. mansoni-infected mice

\begin{tabular}{lll}
\hline Extract & Mean & F-ratio ( $p$-value) \\
\hline V. amygdalina & $12.00 \pm 1.549$ & \\
A. indica & $19.80 \pm 8.194$ & $7.327(0.0026)$ \\
Praziquantel & $13.60 \pm 3.600$ & \\
Untreated & $40.20 \pm 3.072$ & \\
\hline
\end{tabular}

Effect of extracts on the spleen and liver size and weight The relative organ weights of the liver and spleen from $V$. amygdalina, $A$. indica and praziquantel (PZQ)-treated S. mansoni infected mice were all significantly lesser than that of the untreated group $(p<$ 0.05 ) (Fig. 5a and b). The infected group recorded the least relative organ weight $(3.8 \mathrm{~g})$ and the untreated recording the highest $(8.54 \mathrm{~g})$. Treatment groups $(V$. amygdalina and $A$. indica) compared with the untreated group at $p=0.001$ and PZQ compared with the untreated at $p=0.01$ with a slim biological variation (indicated with error bars) in each case.

Effect of extracts on granuloma formations in the liver The liver sections of the infected mice (both treated and non-treated groups) showed granulomas, which appeared as connective tissue fibres formed around an egg. The granuloma formations were severe $(>10)$ among all the untreated group. However, few to moderate granulomas (4 to 10) were observed in the treatment groups (Fig. 6). Granulomas were significantly smaller in diameter in $V$. amydalina and $A$. indica treatment groups than those in the untreated group $(p<0.05)$ (Table 3). Treated cercariae-infected mice group (P, VA and AI) had relatively less severe inflammatory cell infiltration compared with untreated NT group (Fig. 6). 


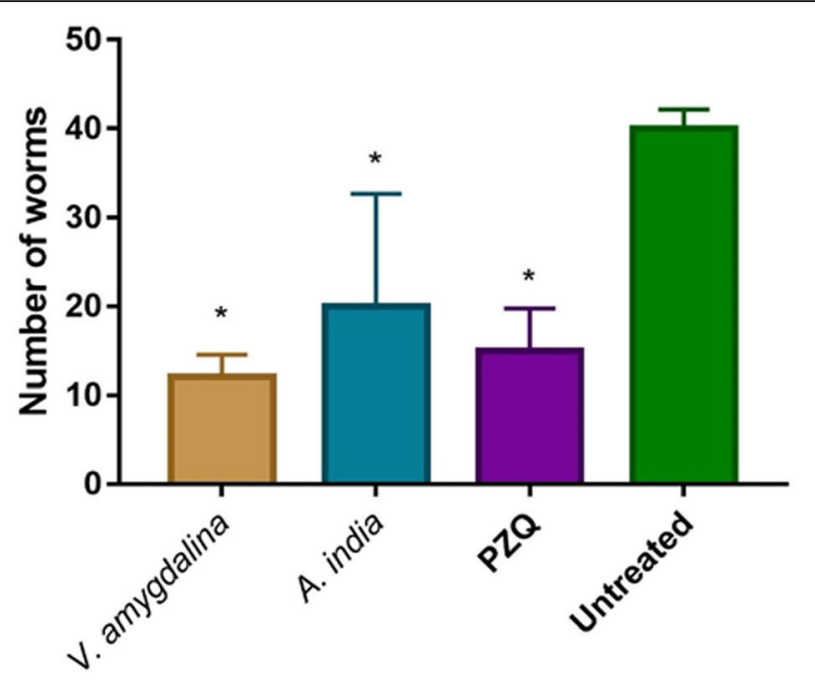

V. amygdalina

$\square$ A. india

$\square \mathrm{PZQ}$

$\square$ Untreated

\section{Treatment groups}

Fig. 3 Mean worms recovered from treatment groups. The number of worms after treatment with the different extracts and PZQ. All treatment group compared with the untreated at $p=0.05$ statistical significance

\section{Discussion}

In both tropical and sub-tropical regions, schistosomiasis is still a major public health concern. Schistosomiasis is prevalent in poor communities, where sanitation is poor and access to potable water is a challenge. Praziquantel is the drug of choice for treating all cases of schistosomiasis; however, cases of treatment failure have been reported in several studies due partly to resistance developed by the parasite towards praziquantel [17-21]. Considering the functional limitations associated with praziquantel, it has become imperative to investigate and discover alternative therapeutic agents with schistosomicidal activity, that are readily available, less expensive, biodegradable and less toxic [22].

This study, therefore, investigated and reports on both in vitro and in vivo effects of the methanolic extract of selected Ghanaian medicinal plants on different life stages of $S$. mansoni, the cercariae and adult worm. The methanolic extracts of the selected plants A. indica, $V$. amygdalina, N. latifolia, P. amarus, and M. lucida demonstrated cercaricidal and schistosomicidal potential in a dose- and time-dependent manner. A. indica exhibited

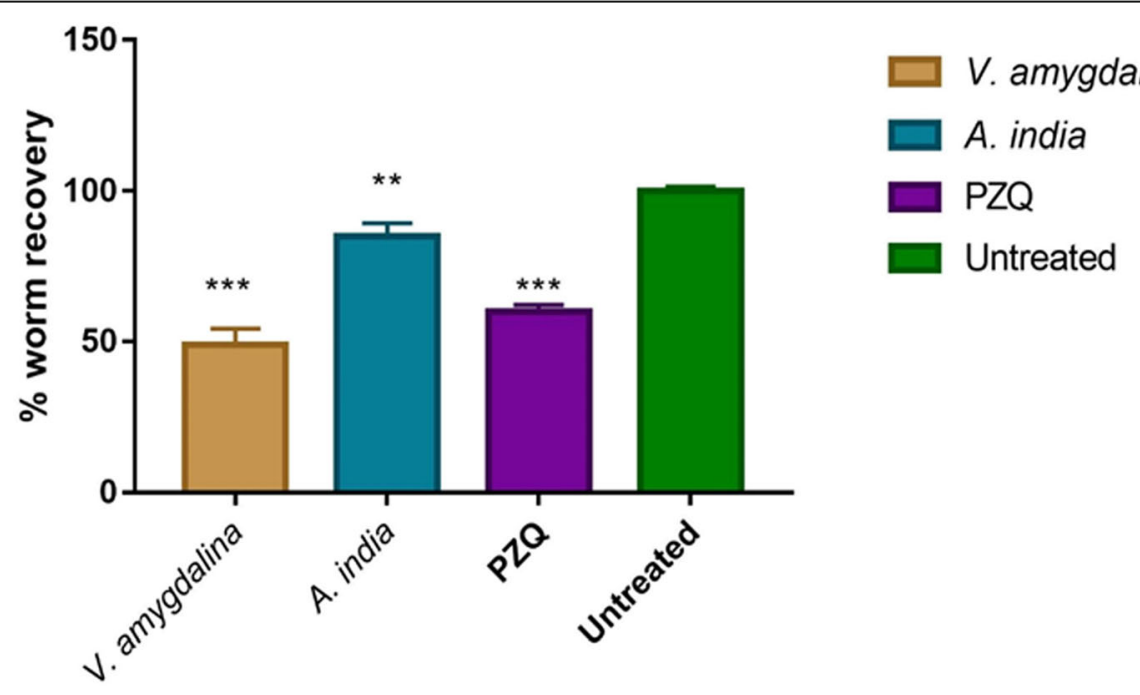

Treatment groups

Fig. 4 Percentage worm recovery 


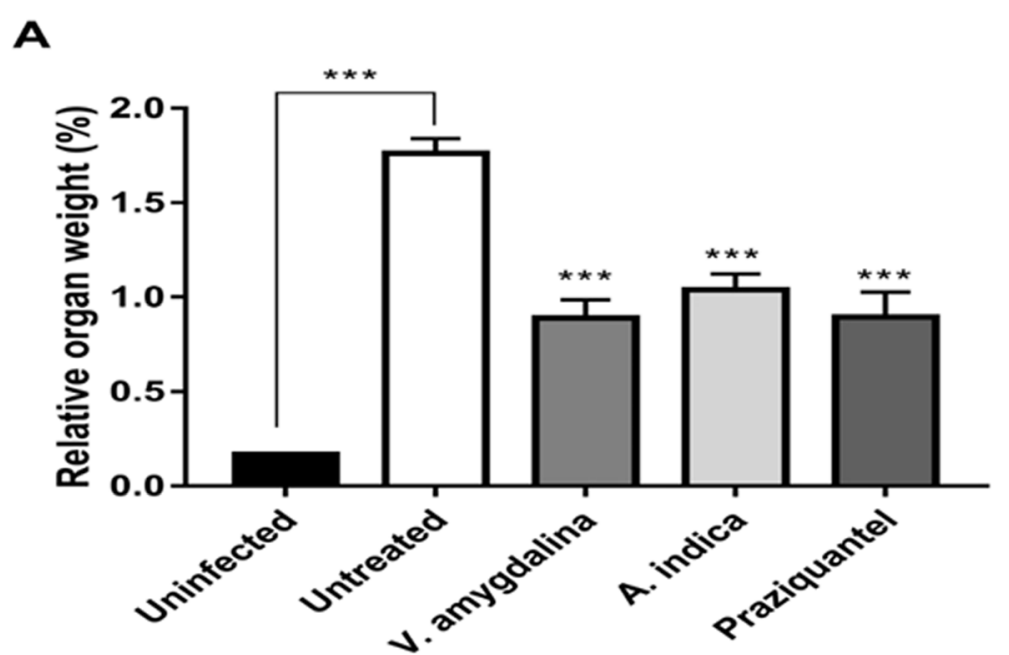

B

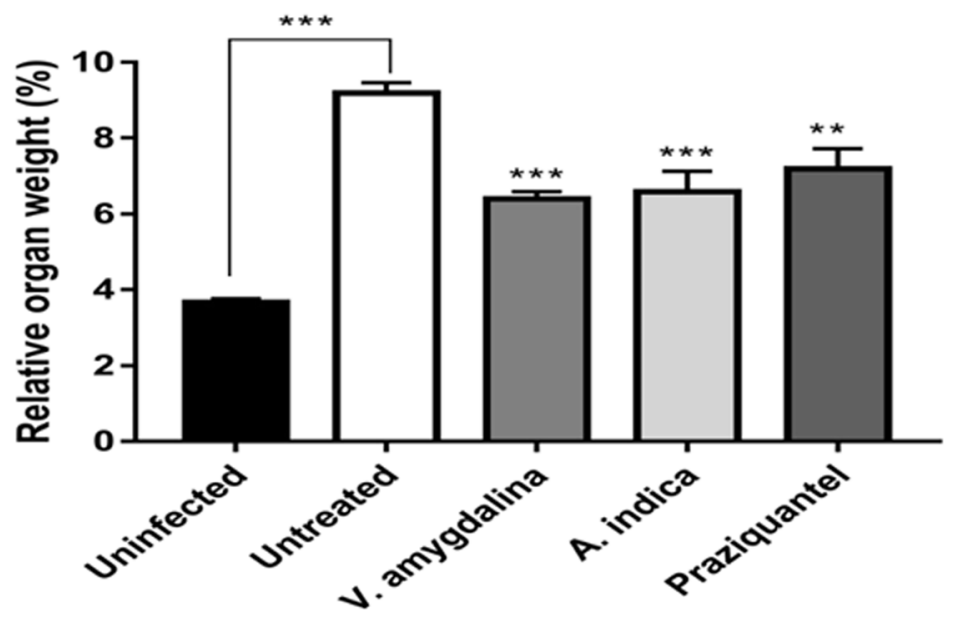

Fig. 5 Relative organ weight (\%) of the various treatment groups

the highest anti-cercarial activity among the plant extracts. Additionally, $A$. indica exhibited the highest in vitro activity against the adult incopula, comparable to that of standard drug praziquantel. Thus, $A$. indica, upon further investigation, could be developed into an alternative agent for the treatment of schistosomiasis. These results corroborate other studies elsewhere [23, 24] and thus, demonstrate that $A$. indica could play an important role in any biological control program aimed at irradicating schistosomiasis. However, at low dose $(<500 \mu \mathrm{g} / \mathrm{mL})$, dose response was not observed for $N$. latifolia, $M$. lucida and $P$. amarus. This observation could be as a result of tolerance of these plants at low doses. This could be possible as cercaria may have been exposed to low doses of these plants in their natural environment.

Statistically, $V$. amydalina has comparable adulticidal activity as $A$. indica in vitro. In contrast, the former registered a relatively higher anti-schistosomal index in vivo. Interestingly, $V$. amygdalina exerted a better adulticidal activity than the standard drug praziquantel in vivo, similar to results reported by Adediran and Uwalaka [25]. Their study proves that $V$. amygdalina is relatively more potent against helminths than conventional drugs ivermectin, levamisole and albendazole, attesting to its efficacy. Additionally, a study by Ogboli et al. [26] also reports that the leaf extracts of $V$. amygdalina have curative effects on mice infected with Schistosoma mansoni [25-28]. Undoubtedly, V. amygdalina demonstrates that it possesses anti-schistosomal activity and should, therefore, be investigated further to derive the full benefit. In this study, the efficacy of $A$. indica and $V$. amygdalina was studied in the same experiment unlike the previous studies. Moreover, these plants were collected from different geographical locations. Again, the efficacy of these plants were compared to others plants whose anti-schistosomal efficacy was not known.

The pairing of the male and female worms in the human host brings about sexual maturation and production of 

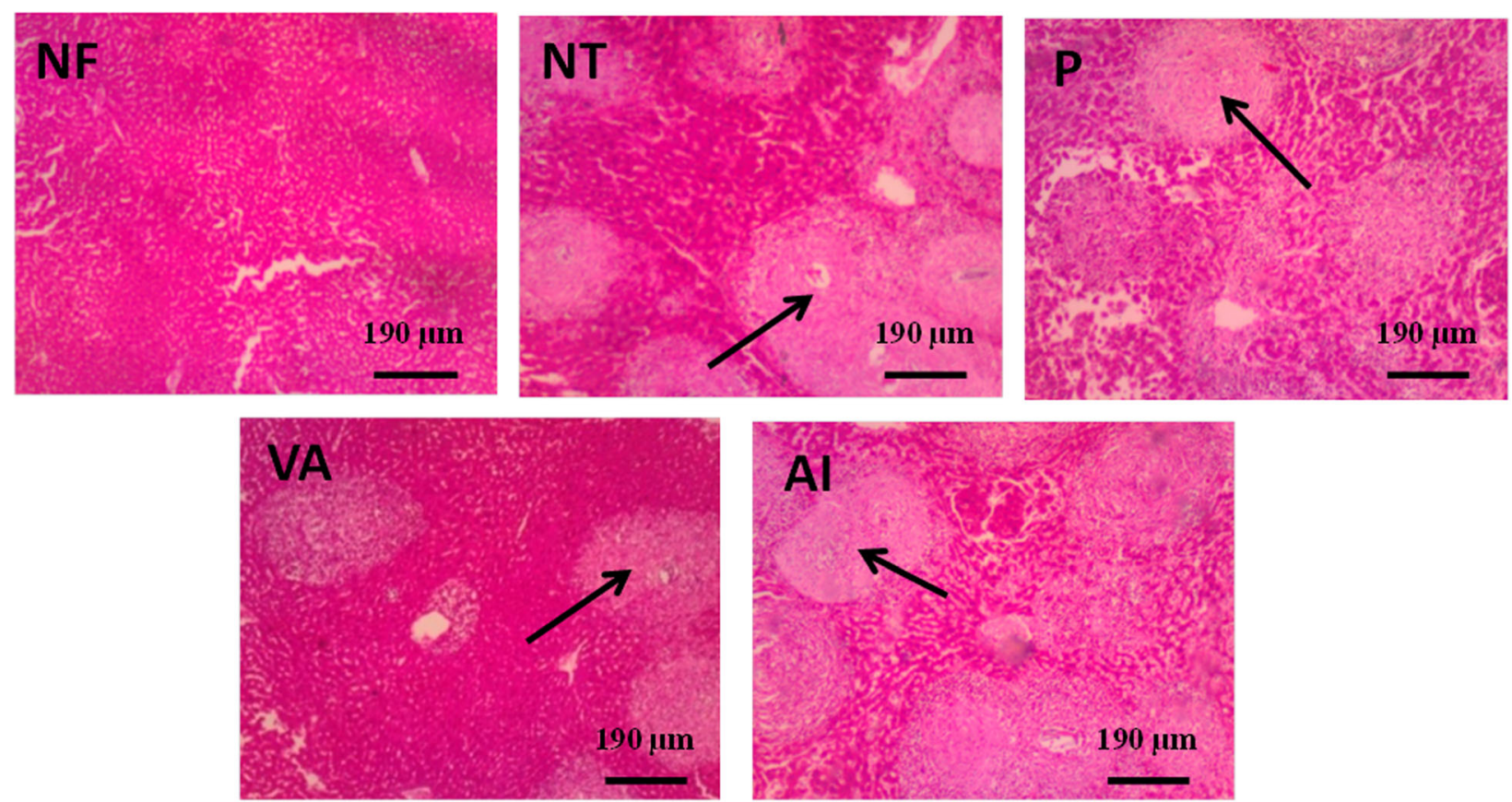

Fig. 6 Photomicrographs (H\&E $\times 200)$ of liver granuloma in S. mansoni-cercariae infected mice from various experimental groups. Single headed arrows ( $\longrightarrow$ ) points to granulomas. NF-mice with no cercariae infection; NT—untreated cercariae infected mice; P-praziquantel-treated cercariae-infected mice; VA—Vernonia amygdalina-treated cercariae-infected mice; Al—A. indica treated cercariae-infected mice

eggs. Moreover, most of the pathologies in schistosomiasis are as a result of the schistosome eggs [28]. The host immune responses towards the eggs and its antigens result into granuloma formation in the liver and hepatosplenomegaly in schistosomiasis patients [29]. In this study, the spleen and liver of the praziquantel-treated cercariaeinfected mice was relatively larger compared to those treated with $V$. amygdalina, suggesting an attenuated hepatomegaly and splenomegaly in the latter group. Furthermore, more granulomas were observed in the hepatic parenchyma of praziquantel-treated mice as opposed to the $V$. amygdalina treated group, further suggesting $V$. amygdalina as better alternative to praziquantel. The acute and sub-acute toxicities of $A$. indica and $V$. amygdalina have been previously reported and were found to be safe $[30,31]$. These plants ability to reduce the size of granulomas is a testament to its efficacy.

Additionally, we are of the view that the activity of $V$. amygdalina is possibly exerted through disruption of adult worm pairing and/or inhibition of egg production in the female worm; hence, few granulomas formed. This could, possibly, be the mechanism of action of $V$. amygdalina; however, more robust molecular techniques have to be employed to establish its mechanism of action.

\section{Conclusion}

All of the five plant extracts, P. amarus, M. lucida, $N$. latifolia, $V$. amygdalina, and $A$. indica exerted varying levels of cercaricidal and adulticidal activities against $S$.

Table 3 Mean diameter of granulomas from liver extract-treated cercariae-infected mice

\begin{tabular}{|c|c|c|c|c|}
\hline Treatment & Mean diameter $(\mu \mathrm{m})$ & 95\% Cl diameter range of granulomas $(\mu \mathrm{m})$ & $p$ value & Post hoc analysis \\
\hline \multirow[t]{3}{*}{ Untreated } & $361.1 \pm 25.02$ & $279.5-392.7$ & $<0.0001$ & A-B 0.0907 \\
\hline & & & & $\mathrm{A}-\mathrm{C} 0.0001^{*}$ \\
\hline & & & & $A-D 0.0005^{*}$ \\
\hline \multirow[t]{2}{*}{ PZQ } & $293.0 \pm 10.90$ & $268.4-317.7$ & & B-C $0.0342^{*}$ \\
\hline & & & & B-D 0.0828 \\
\hline A. indica & $236.3 \pm 7.36$ & $219.9-252.8$ & & C-D 0.6647 \\
\hline V. amygdalina & $245.9 \pm 9.45$ & $223.9-266.6$ & & \\
\hline
\end{tabular}


mansoni. However, whereas A. indica exerted the highest cercaricidal and adulticidal activities in vitro, $V$. amygdalina exhibited the highest schistosomicidal activity in vivo. More importantly, $V$. amygdalina and $A$. indica demonstrated higher activity in vivo and in vitro relative to the respective standard drugs. Hence, $V$. amygdalina and $A$. indica are potential agents for the management of schistosomiasis. Based on the therapeutic potential exhibited by these plant extracts, further studies will be necessary to elucidate the specific compounds responsible for the antischistosomal activities and establish the molecular mechanisms involved. Knowledge of these will facilitate their development into therapeutic agents.

\section{Methods}

Preparation and extraction process of plant specimens The whole plant of $P$. amarus, leaves of $V$. amygdalina and $A$. indica, and both the leaves and bark of M. lucida and $N$. latifolia were collected from the Botanical Gardens of the University of Cape Coast in September 2017. The plant specimens were identified and authenticated at the Herbarium Unit, School of Biological Sciences, University of Cape Coast, Ghana. A voucher specimen $P$. amarus (5152), V. amygdalina (4521), A. indica (3717), M. lucida (3193) and N. latifolia (6623) were kept at the Biological Sciences Herbarium, University of Cape Coast for reference. Dried B. aegyptiaca seeds were obtained from the Herbarium Unit, School of Biological Sciences, University of Cape Coast, Ghana. B. aegyptiaca was used as a positive control due to its known schistosomicidal activity [32, 33] while $A$. indica and $V$. amygdalina have variable antischistosomal activity, $N$. latifolia, $P$. amarus, and $M$. lucida were selected based on their anti-microbial activities in previous studies and their abundance in Ghana.

The extraction was performed adopting a previously described methodology [34] but with few modifications. Fresh parts of each plant specimen were washed and air dried at $25{ }^{\circ} \mathrm{C}$ for 7 days and subsequently in an oven at $40{ }^{\circ} \mathrm{C}$ for 20 min. The dried plant materials were ground into powder. Exactly $400 \mathrm{~g}$ of each pulverized plant material was cold macerated with $800 \mathrm{~mL}$ of absolute methanol at 25 to $30{ }^{\circ} \mathrm{C}$ for $48 \mathrm{~h}$. The mixture was filtered, and the filtrate concentrated using rotary evaporator (Buchi Rotavapor, R 200) under reduced pressure at $40{ }^{\circ} \mathrm{C}$. The crude extract was finally dried in a desiccator and percentage yield of the plant extracts calculated, as shown in supplementary table 1 (table S1).

\section{Experimental animals: maintenance and infection} Maintenance and infection of intermediate snail host, shedding and estimation of cercaria

Matured B. pfeifferi (shell diameter 10-12 mm) snails were maintained in the snail laboratory at the Noguchi Memorial Institute for Medical Research (NMIMR),
Accra, Ghana under standard laboratory conditions of 6.6-8.4 pH, $18-28^{\circ} \mathrm{C}$ and 7-9 dGH $(70-90 \mathrm{ppm}$ of calcium). The snails were each exposed to 4-6 miracidia for 5 weeks. Ten infected snails, observed under light microscope to be shedding cercariae, were then transferred into a test tube containing enough distilled water to submerge them. The snails in the test tube were exposed to artificial light for $120 \mathrm{~min}$ to stimulate cercariae shedding. The cercariae suspension was subsequently drawn into a new test tube and at three different times, $50 \mu \mathrm{L}$ of the cercariae suspension was transferred onto a microscope slide to estimate the number of cercariae per millilitre, using light microscope aided by a tally counter [35]. The cercariae suspension was used for in vitro cercaricidal activity and infection of mice for in vivo adulticidal activity.

\section{Maintenance and infection of mice with cercariae}

Twenty-five 6-week old female ICR mice were purchased from the Animal Experimental Unit of the Centre for Research into Plant Medicine (CRPM), Mampong Akuapem, Ghana. The mice were allowed to acclimatize at the animal housing facility of the School of Biological Sciences, University of Cape Coast for 1 week under the following conditions: 18-23 ${ }^{\circ} \mathrm{C}$ temperature, $40-60 \%$ relative humidity and $12 \mathrm{~h}$ light/dark cycle. The mice were fed on standard pellet diet (Grower Mash, Essaar, Ghana) and provided water ad libitum. Twenty-five (25) of the mice were infected percutaneously as follows. Each mouse was placed in a glass restrainer and its tail then placed in an approximately $n=150 \mathrm{~S}$. mansoni cercariae suspension for $60 \mathrm{~min}$. The mice were handled in accordance with the standard guidelines as enshrined in the "Principles of laboratory animal care" (NIH publication No.85-23, revised 1985) as well as the specific national and institutional requirements regarding the use of animals in scientific studies.

\section{In vitro cercaricidal activity of the plant extracts}

Serial dilutions $(1000 \mu \mathrm{g} / \mathrm{mL}, 500 \mu \mathrm{g} / \mathrm{mL}, 250 \mu \mathrm{g} / \mathrm{mL}$, $125 \mu \mathrm{g} / \mathrm{mL}, 62.5 \mu \mathrm{g} / \mathrm{mL}$ and $31.25 \mu \mathrm{g} / \mathrm{mL}$ ) of each of the test plant extracts were prepared using distilled water as diluent. Two millimetre of each dilution was added to three wells of a 6-well culture plate. Approximately thirty cercariae were then pipetted into each of the wells. The wells were observed using an inverted light microscope at specific time intervals: $15,30,60,90,120,150$ and $180 \mathrm{~min}$. The number of dead cercariae at various time points was counted. Balanites aegyptiaca was used as positive control and RPMI $+1 \%$ dimethyl sulfoxide (DMSO) as the negative control.

\section{In vitro evaluation of the anti-schistosomal activity}

In vitro adulticidal activity was carried out as described previously [36] with few modifications. Five 8-week old 
S. mansoni cercariae-infected mice were randomly selected, euthanized with intraperitoneal injections of pentobarbital/heparin solution. Perfusate citrate saline (0.85\% sodium chloride; $1.5 \%$ sodium citrate) was pumped into the descending thoracic aorta using a 20 gauge needle. A slit was made in the hepatic portal vein and the perfusate was collected into a container for adult worms' recovery. The recovered worms were washed thrice with phosphate-buffered saline (PBS) $(\mathrm{pH}=7.4)$ and finally in RPMI 1640 medium. Subsequently, incopula adult worms were picked into each well of a 24well culture plate containing RPMI 1640 medium supplemented with $1 \%$ HEPES, $10 \%$ fetal bovine serum (FBS) and $100 \mu \mathrm{g} / \mathrm{mL}$ penicillin. A $2 \mathrm{~mL}$ of $1000 \mu \mathrm{g} / \mathrm{mL}$, $500 \mu \mathrm{g} / \mathrm{mL}, \quad 250 \mu \mathrm{g} / \mathrm{mL}, \quad 125 \mu \mathrm{g} / \mathrm{mL}, \quad 62.5 \mu \mathrm{g} / \mathrm{mL}$ and $31.25 \mu \mathrm{g} / \mathrm{mL}$ of the plant extracts were added to the well in triplicates, each containing a pair of the worms. Some of the paired worm-wells were treated with either $20 \mu \mathrm{g} / \mathrm{mL}$ praziquantel or RPMI 1640 medium with supplements $+1 \%$ DMSO to serve as positive and negative controls, respectively. The plates were then incubated at $37^{\circ} \mathrm{C}$ with $5 \% \mathrm{CO}_{2}$ for $120 \mathrm{~h}$ and observed under an inverted microscope at 24-h interval. The medium was also changed every $48 \mathrm{~h}$ to ensure that there was sufficient nutrient for the worms. Viability of the worms per well was scored as follows: 0 -worm dead; 1 -severe reduction in motility and morphological changes; 2-reduced motility and first morphological changes; and 3-vital, normally active and no morphological changes.

\section{In vivo treatment with plant extracts and granuloma size determination}

Nine-week $S$. mansoni cercariae-infected mice were randomly put into four groups of five: infected mice $+A$. indica $(500 \mathrm{mg} / \mathrm{kg}$ po), infected mice $+V$. amygdalina $(500 \mathrm{mg} / \mathrm{kg}$ po), infected mice + praziquantel $(400 \mathrm{mg} / \mathrm{kg}$ po $)$ and infected mice + distilled water (infected control). The two plant extracts, A. indica and $V$. amygdalina were selected based on their better activity against the adult worms in vitro. Two weeks after treatment, the mice were anaesthetised with sodium citrate and perfused with normal saline for adult worm recovery and counting with the aid of an inverted microscope (Olympus CK 300). The percentage worm recovery was calculated as follows: \% worm recovery $=$ mean of total worms in experimental group/mean of total worms in infected control $x$ $100 \%$. Also, total number of paired adult worms per mouse was recorded as the worm burden. The liver and spleen were isolated after which, the weight and organ to body weight of the various treatment groups were determined.

\section{Histopathological examination of the liver tissues}

The right lobe of the liver from each mouse was fixed in $10 \%$ buffered formalin and taken through routine histological processes previously described by Gyasi et al. [37]. After trimming of tissue block, random sections (5.0- $\mu \mathrm{m}$ thickness) were stained with haematoxylin-eosin (HE). With the aid of the light microscope (Olympus CX41RF) coupled to a digital camera (Olympus soft imaging solutions $\mathrm{GMBH}$ ), granulomas, which presented as fibrous connective tissue surrounding an ovum were identified and counted. The cross-sectional areas of the granulomas were determined using an integrated measurement tool of the LMscope software (Micro-Tech Lab, Austria). The granulomas in the livers were grouped as none ( 0$)$, few ( 1 to 3$)$, moderate ( 4 to 10$)$ and severe (> 10) granulomas per liver with reference to their mean diameters [38].

\section{Statistical analysis}

All data were expressed as mean \pm standard deviation (SD). A time-course percent mortality and time-course viability scale line graphs were created for in vitro anticercarial and antischistosomal activities respectively. GraphPad Prism for Windows version 4.03 (GraphPad Software, San Diego, CA, USA) was used for all statistical analyses. $\mathrm{p}<0.05$ was considered statistically significant.

\section{Supplementary information}

Supplementary information accompanies this paper at https://doi.org/10. 1186/s41182-020-00205-y.

Additional file 1. Supplementary Tables and Figures.

\section{Abbreviations}

ANOVA: Analysis of variance; DMSO: Dimethyl sulfoxide; FBS: Fetal bovine serum; HE: Hematoxylin eosin; NMIMR: Noguchi Memorial Institute of Medical research; NTDs: Neglected tropical diseases; PZQ: Prazequantel

\section{Acknowledgements}

Not applicable

Authors' contributions

DOA, WKA, and NO-A conceived and designed the study. DOA, WKA, NO-A, $F A A$, and EA performed the experimental work as well as the histological analysis. DOA, WKA, NO-A, AKT, EAA, and EA analyzed all the data, prepared and edited the manuscript. All authors approved the final version of the manuscript.

\section{Funding}

Funding for this study was provided by authors of the study

Availability of data and materials

All data generated or analyzed during this study are included in this published article.

Ethics approval and consent to participate

Ethical approval was obtained from the University of Cape Coast Institution Review Board.

Consent for publication

Not applicable 


\section{Competing interests}

The authors declare that they have no competing interests.

\section{Author details}

'Department of Biomedical Sciences, School of Allied Health Sciences, College of Health and Allied Science, University of Cape Coast, Cape Coast, Ghana. ${ }^{2}$ Department of Biomedical Sciences, School of Basic and Biomedical Sciences, University of Health and Allied Sciences, HoVolta RegionGhana. ${ }^{3}$ Noguchi Memorial Institute for Medical Research, College of Health Sciences, University of Ghana, Legon, Ghana.

\section{Received: 27 December 2019 Accepted: 25 March 2020}

\section{Published online: 10 April 2020}

\section{References}

1. Hotez PJ. NTDs V. 2.0:"blue marble health"—-neglected tropical disease control and elimination in a shifting health policy landscape. PLOS Negl Trop Dis. 2013;7(11):e2570. https://doi.org/10.1371/journal.pntd.0002570.

2. King CH, Olbrych SK, Soon M, Singer ME, Carter J, Colley DG. Utility of repeated praziquantel dosing in the treatment of schistosomiasis in highrisk communities in Africa: a systematic review. PLOS Negl Trop Dis. 2011; 5(9):e1321.

3. Thétiot-Laurent SAL, Boissier J, Robert A, Meunier B. Schistosomiasis chemotherapy. Angew Chem. 2013;52(31):7936-56.

4. Misra L, Wouatsa NV, Kumar S, Kumar RV, Tchoumbougnang F. Antibacterial, cytotoxic activities and chemical composition of fruits of two Cameroonian Zanthoxylum species. J Ethnopharmacol. 2013;148(1):74-80.

5. WHO. World malaria report 2014. Geneva: World Health Organization; 2015.

6. Stete K, Krauth SJ, Coulibaly JT, Knopp S, Hattendorf J, Müller I, Utzinger J. Dynamics of Schistosoma haematobium egg output and associated infection parameters following treatment with praziquantel in school-aged children. Parasit Vectors. 2012;5:298. https://doi.org/10.1186/1756-3305-5298.

7. Farid Z. Schistosomes with terminal-spined eggs: pathological and clinical aspects. Biology. 1993:159-93.

8. Olds G, King C, Hewlett J, Olveda R, Wu G, Ouma J, Koech D. Double-blind placebo-controlled study of concurrent administration of albendazole and praziquantel in schoolchildren with schistosomiasis and geohelminths. J Infect. 1999;179(4):996-1003.

9. Anto F, Asoala V, Adjuik M, Anyorigiya T, Oduro A, Akazili J, et al. Water contact activities and prevalence of schistosomiasis infection among school-age children in communities along an irrigation scheme in rural northern Ghana. J Bacteriol Parasitol. 2013;4:117. https://doi.org/10.4172/ 2155-9597.1000177.

10. Bosompem KM, Bentum IA, Otchere J, Anyan WK, Brown CA, Osada Y, et al. Infant schistosomiasis in Ghana: a survey in irrigation community. Trop Med Int Health. 2004;9(8):917-22.

11. Wang T, Zhao M, Rotgans BA, Strong A, Liang D, Ni G, et al. Proteomic analysis of the Schistosoma mansoni Miracidium. PLoS ONE. 2016;11(1). https://doi.org/10.1371/journal.pone.0147247.

12. Rates SMK. Plants as source of drugs. Toxicon. 2001;39(5):603-13.

13. Dhama K, Tiwari R, Chakraborty S, Saminathan M, Kumar A, Karthik K, Rahal A. Evidence based antibacterial potentials of medicinal plants and herbs countering bacterial pathogens especially in the era of emerging drug resistance: an integrated update. Int J pharmacol. 2014;10(1):1-43.

14. Truiti MDT, Sarragiotto MH, Abreu FBA, Nakamura CV, Dias FBP. In vitro antibacterial activity of a 7-O- $\beta$-D-glucopyranosyl-nutanocoumarin from Chaptialia nutans (Asteraceae). Mem. Inst. Oswaldo Cruz. 2003;98:283-6.

15. Oliveira CN, Frezza TF, Garcia VL, Allergretti S. Schistosoma mansoni: in vivo evaluation of Phyllanthus amarus hexanic and ethanolic extracts. Experimental Parasitology. 2017;183.

16. Agyare C, Spiegler V, Sarkodie H, Asase A, Liebau E, Hensel A. An ethnopharmacological survey and in vitro confirmation of the ethnopharmacological use of medicinal plants as anthelmintic remedies in the Ashanti region, in the central part of Ghana. J Ethnopharmacol. 2014; 158:255-63.

17. Groning E, Bakathir H, Salem A, Albert L, Fernández R. Efectividade y tolerancia de praziquantel. Rev Cub Med Trop. 1985;37:215-9.

18. Herwaldt BL, Tao L, Van Pelt W, Tsang VC, Bruce Jl. Persistence of Schistosoma haematobium infection despite multiple courses of therapy with praziquantel. Clin Infect Dis. 1995;20:309-15.
19. Hatz CF, Vennervald BJ, Nkulila T, Vounatsou P, Kombe Y, Mayombana C, Mshinda H, Tanner M. Evolution of Schistosoma haematobium - related pathology over 24 months after treatment with praziquantel among school children in southeastern Tanzania. Am J Trop Med Hyg. 1998;59:775-81.

20. Ernould JC, Ba K, Sellin B. Increase of intestinal schistosomiasis after praziquantel treatment in Schistosoma haematobium and Schistosoma mansoni mixed focus. Acta Trop. 1999;73:143-52.

21. Liang YS, Coles GC, Doenhoff MJ. Short communication: Detection of praziquantel resistance in schistosomiasis. Trop Med Int Health. 2000;5:72.

22. Abara SM. Treatment of schistosomiasis: from praziquantel to development of new drug targets. PUJ. 2013;6(2):127-48.

23. Musili R, Muregi F, Mwatha J, Muriu D, M'Rewa L, Kamau T, Menaine A, Chege S, Thiong'o J, Ng'ang'a Z, Kimani G. Antischistosomal activity of Azadirachta Indica and Ekebergia capensis in mice infected with Schistosoma mansoni. Eur J Med Plants. 2015;6(2):92-102.

24. Quelemes PV, Perfeito ML, Guimarães MA, dos Santos RC, Lima DF, Nascimento C, Silva MP, Soares MJ, Ropke CD, Eaton P, et al. Effect of neem (Azadirachta indica A. Juss) leaf extract on resistant Staphylococcus aureus biofilm formation and Schistosoma mansoni worms. J Ethnopharmacol. 2015;175:287-94.

25. Adediran OA, Uwalaka EC. Effectiveness evaluation of levamisole, albendazole, ivermectin, and Vernonia amygdalina in West African dwarf goats. J Parasitol Res. 2015. https://doi.org/10.1155/2015/706824.

26. Ogboli A, Nock I, Obdurahman E, Ibrahim N. Medicinal application of Vernonia amygdalina del leaf extracts in the treatment of schistosomiasis in mice. Nigerian J Nat Products Med. 2000;4(1):73-5.

27. Yeap SK, Ho WY, Beh BK, San Liang W, Ky H, Yousr AHN, Alitheen NB. Vernonia amygdalina, an ethnoveterinary and ethnomedical used green vegetable with multiple bio-activities. J Med Plant Res. 2010;4(25):2787-812.

28. Burke JM, Jones MK, Gobert GN, Li YS, Ellis MK, McManus DP. Immunopathogenesis of human schistosomiasis. Parasite Immunol. 2009;31: 163-76.

29. Ross AG, Olds GR, Cripps AW, Farrar JJ, McManus DP. Enteropathogens and chronic illness in returning travellers. N Engl J. Med. 2013;368:1817-25.

30. Deng YX, Cao M, Shi DX, Yin ZQ, Jia RY, Xu J, Wang C, Lv C, Liang XX, He $\mathrm{CL}$, Yang ZR, Zhao J. Toxicological evaluation of neem (Azadirachta indica) oil: acute and subacute toxicity. Environ Toxicol Pharmacol. 2013;35(2):2406.

31. Akowuah GA, May LLY, Chin JH. Toxicological evaluation of Vernonia amygdalina methanol leave extract in rats. Orient Pharm Exp Med. 2015;15: 365-9. https://doi.org/10.1007/s13596-015-0194-6.

32. Eshetu M. G, Berhanu E. Laboratory assessment of the molluscicidal and cercariacidal activities of Balanites aegyptiaca. Asian Pac J Trop Biomed. 2013;3(8):657-62.

33. Koko WS, Abdalla HS, Galal M, Khalid HS. Evaluation of oral therapy on mansomal schistosomiasis using single dose of Balanites aegyptiaca fruits and praziquantel. Fitoterapia. 2005;76:30-4.

34. Anowi CF, Cardinal NC, Mbah C, Onyekaba T. Antimicrobial properties of the methanolic extract of the leaves of Nauclea latifolia. IJDRT. 2017;2(1):10.

35. Sturrock B, Sturrock R. Laboratory studies of the host-parasite relationship of Schistosoma mansoni and Biomphalaria glabrata from St Lucia, West Indies. Ann Trop Med PH. 1970;64(3):357-63.

36. Saleh M, Glombitza K. Volatile oil of Marrubium vulgare and its antischistosomal activity. Planta Medica. 1989;55(01):105.

37. Gyasi SF, Awuah E, Asiedu LJA, Koffuor GA, Debrah AY, Awua-Boateng NY, Osei O-A. Susceptibility of arsenic-exposed ICR mice to buruli ulcer development. Pharmacologia. 2013:4:254-64.

38. Mahmoud M, El-Abhar H, Saleh S. The effect of Nigella sativa oil against the liver damage induced by Schistosoma mansoni infection in mice. J Ethnopharmacol. 2002;79(1):1-11.

\section{Publisher's Note}

Springer Nature remains neutral with regard to jurisdictional claims in published maps and institutional affiliations. 